\title{
Factors Impacting on Decision-Making towards Prophylactic Surgeries in BRCA Mutation Carriers and Women with Familial Predisposition
}

\author{
Robin Segerer $^{a} \quad$ Clara Peschel $^{b} \quad$ Ulrike Kämmerer $^{c} \quad$ Sebastian Häussler ${ }^{d}$ \\ Achim Wöckel ${ }^{c}$ Sabine Segerer ${ }^{\mathrm{e}}$ \\ ${ }^{a}$ Institut für Psychologie, Universität Basel, Basel, Switzerland; ${ }^{b}$ Klinikum Stuttgart - Krankenhaus Bad Cannstatt,

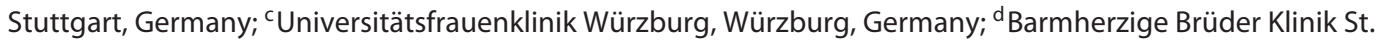

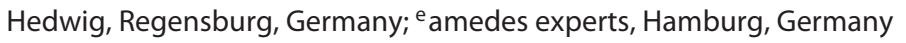

\section{Keywords}

$B R C A \cdot$ Hereditary breast cancer $\cdot$ Breast cancer

\begin{abstract}
Background/Objectives: BRCA mutation carriers and women at high risk of breast/ovarian cancer are faced with the intricate question to opt for prophylactic surgeries and/or a periodic screening. The aim of this study was therefore to identify objective and emotional factors that have an impact on the decision-making process. Methods: Ninety-five women with BRCA mutations or women at increased breast/ovarian cancer lifetime risk were counseled at our outpatient department and either opted for prophylactic surgery or periodic screening. To identify the psychological factors that could have influenced the decision-making, a standardized questionnaire was applied. Additionally, clinical data were collected and were reviewed by a personal talk. Results: Seventy-one of the patients opted for an increased surveillance only, 21 for prophylactic surgeries. Positive predictors for prophylactic surgeries were sociodemographic characteristics such as parity and objective variables such as verified mutation status. Hierarchical regression analysis revealed that the need for safety in health issues has been the only significant psychological predictor of surgery beyond the objective factors. Fear of surgical procedures, menopausal symptoms after surgery, loss of attractiveness, or fear of interferences with sexual life did not significantly affect decision-making. Conclusion: Decision-making towards prophylactic surgeries is influenced by objective but also emo-
\end{abstract}

tional factors. Knowing that fear and anxiety also have an important impact on decision-making, distinct counselling about the procedures, the subsequent risk reduction as well as the psychological effects of prophylactic surgeries are essential.

(c) 2019 S. Karger AG, Basel

\section{Introduction}

The risk for breast cancer (BC) and ovarian cancer (OC) is associated with the number of the relatives affected [1]. Among hereditary BCs and OCs, about half of all monogenetically determined cases are due to a mutation of the two BRCA genes [2]. Women with mutations in the BRCA1 or BRCA2 gene have an estimated lifetime risk of $\mathrm{BC}$ of $56-84 \%$ and a lifetime risk for OC of $54 \%$ (BRCA1) or $27 \%$ (BRCA2), respectively [3, 4]. Additionally, the risk for contralateral $\mathrm{BC}$ is increased for women with $B R C A$ mutations and diagnosed $\mathrm{BC}$ [5].

$B R C A 1 / B R C A 2$ mutation carriers or women at increased lifetime risk of $\mathrm{BC} / \mathrm{OC}$ are counseled about prevention guidelines and screening options for early diagnosis.

Prophylactic surgeries are considered the most effective strategies to reduce cancer incidence in mutation carriers [6]. Thereby, risk-reducing bilateral salpingo-oophorectomy (RRBSO) is even associated with significantly lower all-cause mortality in $B R C A 1 / 2$ mutation carriers [6-9]. Additionally, all-cause mortality was significantly 
lower after contralateral prophylactic mastectomy in $B R C A$ mutation carriers with $\mathrm{BC}[6]$.

Alternatively, secondary prevention options such as increased surveillance for early detection of cancer (magnetic resonance imaging in addition to annual mammography) can be offered [10]. However, studies did not detect an increase in overall-survival by annual mammography and magnetic resonance imaging screening so far [11].

Even though prophylactic surgeries have been shown to be partly associated with survival benefits for $B R C A$ mutation carriers (without cancer diagnosis), only few decide to realize them [12]. Summarizing the data of nine countries (without Germany), Metcalfe et al. [12] have reported that $18 \%$ of the women with $B R C A 1$ or $B R C A 2$ mutation without $\mathrm{BC}$ had undergone risk-reducing mastectomy (RRM). Approximately one-half of the women with $B R C A 1 / B R C A 2$ mutation opted for screening solely. In contrast, this study showed that RRBSO was widely accepted by women with BRCA1/BRCA2 mutations (57.2\% RRBSO). A German cohort study reported about 12/27 (44\%) mutation carriers (without BC) to opt for RRM [13].

Previous studies revealed that the acceptance of prophylactic surgeries is affected by several internal and external variables. Concerning external variables, national care access and provider recommendations seem to matter, but also the health knowledge of one's own [14]. Internal factors comprise sociodemographic characteristics such as education or parity. These have also been shown to be positive predictors of prophylactic surgeries [15]. Beyond that, psychosocial variables such as general health perception, perceived incurability of cancer, and perceived benefits of surgery seem to have an impact on decision-making in favor of prophylactic surgery. In contrast, emotional factors such as anxiety, vulnerability, and change in body image/sexuality have been reported to hamper the decision in favor of prophylactic surgeries [15-17].

Therefore, the aim of our study was to quantify the effects of (i) health- and cancer-related knowledge; (ii) internal or external factors that could influence decisionmaking in favor of prophylactic surgeries; and (iii) the detection of specific fears that could be in conflict with the decision in favor of prophylactic surgeries.

\section{Materials and Methods}

Inclusion criteria were identified $B R C A 1$ and/or $B R C A 2$ mutation or a significantly increased lifetime risk of BC/OC (>30\%) without known mutations [2]. Only patients beyond 25 years of age were included. Prior to the study, all participants had an individual discussion with the physician geneticist as well as the gynecologist about the individual lifetime risk as well as prevention options including general health issues and prophylactic surgeries. The online supplementary questionnaire (for all online suppl. material, see www.karger.com/doi/10.1159) addressing the different topics of decision-making (additional material) was offered to all women after this talk in the outpatient department of gynecology.

Clinical information about sociodemographic characteristics and objective internal variables (mutation status/individual genetic risk, family, and personal history of $\mathrm{BC} / \mathrm{OC}$ including subsequent therapies) were collected by medical reports and were reviewed in a personal talk with the patient. Additionally, reproductive history as well as general health care issues were noted.

\section{Knowledge about Hereditary BC and OC and General Health}

Care

Women's knowledge about general health and their special knowledge about hereditary BC and OC was evaluated using eight items. We assessed women's knowledge about the effectiveness of measures against cancer and the concrete use of alternative medicines.

Women were also asked to rate their individual risk for $\mathrm{BC} / \mathrm{OC}$ using a 5-point Likert scale item (very low to very high) in the online supplementary questionnaire. These subjective risk assessments were regressed in a single regression to the actual genetic risk. The residual values of this estimate serve as a $z$-standardized measure of a patient's over- or underestimation of her actual cancer risk.

\section{Motivating Factors That Suggest Prophylactic Surgery versus}

Intensified Screening

Four items asked about internal and external factors that could motivate women to undergo prophylactic surgery. Women were asked to rate the potential motivational impact of a possible detection of cancer, a possible recurrence of cancer in their family, and the patients' general fear of cancer. A further question asked to what extent the patients were convinced that prophylactic surgeries would be more effective against cancer than intensified screening.

The barriers against RRM or RRBSO were addressed in 18 subscaled items. Here, questions asking for specific fears were included (weight gain and menopausal symptoms, loss of attractiveness, rejection by the partner, disordered female identity, interferences with sex life, surgical measures). Another question assessed the belief that increased surveillance was safe enough as a cancer prevention. Questions that may refer to both mastectomy and RRBSO were asked in relation to these two surgical interventions. The two ratings were averaged.

\section{General Health Care}

Questions about general health (smoking status, medications, supplementary medicine, physical activity, nutrition) of the participants were addressed in four different items in the online supplementary questionnaire. Additionally, women's BMI was noted.

\section{Statistical Analysis}

We carried out a hierarchical logistic regression analysis with $\mathrm{RRM} / \mathrm{RRBSO}$ versus no surgery as the criterium variable. Sociodemographic and psychosocial control variables were entered as predictors in a first step. Perceived barriers and benefits of the operative and nonoperative procedures were included in the second step. Due to the small sample size only variables with significant bivariate correlations with the surgery decision were included in the model. Statistical significance was assessed at the two-sided $p<0.05$ level. All analyses were conducted using SPSS 22 (IBM, 20xx). 
Table 1. Sociodemographic characteristics of women with/without RRM or RRBSO

\begin{tabular}{lcccc}
\hline Demographic characteristics & No RRM/RRBSO & RRM/RRBSO & $p$ & ES $(d / \mathrm{OR})$ \\
\hline Age, years & $44.87(10.98)$ & $46.44(8.29)$ & 0.48 & $0.15^{\mathrm{b}}$ \\
Parity (at least one child) & 66 & 90 & $0.03^{*}$ & $4.85^{\mathrm{a}}$ \\
Breastfeeding (yes) & 64 & 47 & 0.42 & $0.85^{\mathrm{a}}$ \\
Mutation type/risk status & & & & \\
$\quad$ BRCA1 (yes) & 20 & 43 & $0.045^{*}$ & $8.67^{\mathrm{a}}$ \\
BRCA2 (yes) & 8 & 29 & $0.03^{*}$ & $15.33^{\mathrm{a}}$ \\
High risk (yes) & 72 & 28 & $<0.01^{*}$ & $0.46^{\mathrm{a}}$ \\
Surgery before baseline (yes) & 35 & 52 & 0.20 & $2.02^{\mathrm{o}}$ \\
BMI & $25.01(4.71)$ & $28.48(11.90)$ & 0.20 & $0.51^{\mathrm{b}}$ \\
Smoking (yes) & 20 & 16 & $>0.99$ & $0.75^{\mathrm{a}}$ \\
Physical activities (yes) & 77 & 89 & 0.34 & $2.57^{\mathrm{a}}$ \\
Use of alternative medicine (yes) & 29 & 26 & 0.54 & $0.88^{\mathrm{a}}$ \\
\hline
\end{tabular}

Values are presented as percentages or mean (SD). RRM, risk-reducing mastectomies; RRBSO, risk-reducing

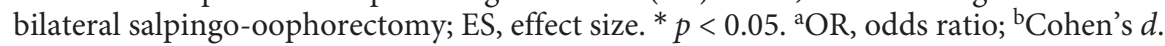

\section{Results}

\section{Sociodemographic Characteristics of Patients with RRM/RRBSO}

The data of 95 patients were analyzed. Three patients were excluded because it was not possible to determine whether the patient underwent surgery, resulting in a final sample of $n=92$. Our sample included $23 B R C A 1$ mutation carriers, $12 B R C A 2$ mutation carriers as well as 57 patients with a significantly increased lifetime risk for $\mathrm{BC} / \mathrm{OC}$ without specific detection of a mutated gene. Twenty-one out of 92 patients underwent surgery after the screening (3 RRM, 17 RRBSO, 1 RRM, and RRBSO). Table 1 describes all sociodemographic data of the patients with and without prophylactic surgery. Analyzing the age of the patients with/without prophylactic surgeries, we did not detect significant differences between the two groups. Parity was significantly higher of women with prophylactic surgeries. However, breastfeeding, smoking, physical activity, or the use of alternative medicine was not significantly more prevalent in one group. Patients with detected mutation status (BRCA1 or BRCA2 vs. high risk) opted significantly more often for RRM/ RRBSO than nonmutation carriers. Previous curative/ elective surgeries did not significantly influence decisionmaking towards prophylactic surgeries.

\section{Psychological Variables for RRM/RRBSO}

Women who opted for prophylactic surgery attributed to RRBSO more effect than women who did not undergo surgery. Beyond that, there were no significant differences in health-related knowledge.

For women who opted for prophylactic RRM/RRSO, the need for safety in health issues was a more significant reason to participate in screening than for women who did not undergo surgery (Table 2). The RRM/RRSO group also reported a greater fear of far-reaching therapeutic measures as a reason to participate in the screening compared to the non-surgery group.

Fear to come down with cancer was the only psychological factor that was stronger in the prophylactic surgery group than in the non-surgery group. The fears of rejection by the partner, an impaired sexual life, loss of attractiveness, or a disturbed female identity did not significantly correlate with decision-making. Fear of surgical interventions or menopausal symptoms after surgery also had no significant effects.

We entered all objective and psychological variables significantly correlating with the surgery decision into a logistic regression analysis. It revealed that the need for safety in health issues was the only significant psychological predictor of surgery beyond the objective factors parity, BRCA1, and BRCA2 mutation status (Table 3).

\section{Discussion and Conclusion}

Despite increased awareness of prophylactic surgeries due to $B R C A$ mutations in the public, studies revealed that the public discussion did neither improve the understanding of hereditary BC and OC in the United States of America nor the understanding of the benefits of prophylactic surgeries for $B R C A 1 / 2$ mutation carriers [17-19].

In our cohort study, we investigated the reasons for or against the uptake of RRM/RBSO or prophylactic screening of women with BRCA1/BRCA2 mutation and in those with a $>30 \%$ increased lifetime risk for BC and OC. 
Table 2. Psychological variables (mean comparisons) of women with/without RRM or RRBSO

\begin{tabular}{|c|c|c|c|c|c|c|}
\hline & \multicolumn{2}{|c|}{ No RRM/RRBSO } & \multicolumn{2}{|c|}{ RRM/RRBSO } & \multirow[t]{2}{*}{$p$} & \multirow[t]{2}{*}{$E S(d)$} \\
\hline & $n$ & mean $(\mathrm{SD})$ & $n$ & mean $(\mathrm{SD})$ & & \\
\hline \multicolumn{7}{|l|}{ Health-related knowledge } \\
\hline \multicolumn{7}{|l|}{ Perceived cancer preventive effect of... } \\
\hline RRM & 62 & $2.97(1.22)$ & 21 & $2.74(1.49)$ & 0.85 & -0.18 \\
\hline RRBSO & 64 & $2.97(1.10)$ & 19 & $3.57(0.75)$ & $<0.01^{*}$ & 0.46 \\
\hline Healthy lifestyle & 70 & $3.31(0.77)$ & 21 & $3.62(0.59)$ & 0.06 & 0.43 \\
\hline Intense care & 70 & $3.74(0.67)$ & 20 & $3.74(0.92)$ & 0.82 & 0.00 \\
\hline Abstention from hormone supplements & 60 & $2.87(1.03)$ & 18 & $3.33(1.03)$ & 0.10 & 0.45 \\
\hline Organic food & 70 & $2.16(1.21)$ & 21 & $2.29(1.19)$ & 0.67 & 0.11 \\
\hline \multicolumn{7}{|l|}{ Perceived risk of BC/OC controlled for } \\
\hline estimated objective risk ( $z$-score) & 66 & $0.15(0.90)$ & 16 & $-0.38(1.12)$ & 0.11 & -0.56 \\
\hline \multicolumn{7}{|l|}{ Reasons to participate in screening } \\
\hline Need for safety in health issues & 69 & $3.36(0.80)$ & 21 & $3.71(0.56)$ & $0.03^{*}$ & 0.47 \\
\hline Possibility of early cancer detection & 69 & $3.83(0.38)$ & 21 & $3.86(0.36)$ & 0.74 & 0.08 \\
\hline Fear of far-reaching therapeutic measures & 67 & $3.31(0.80)$ & 21 & $3.76(0.54)$ & $<0.01^{*}$ & 0.60 \\
\hline Cost assumption by the study & 69 & $3.33(0.83)$ & 21 & $3.48(0.60)$ & 0.47 & 0.19 \\
\hline Gynecologist's recommendation & 68 & $3.01(1.15)$ & 20 & $3.05(1.05)$ & 0.90 & 0.04 \\
\hline Recommendation by media & 67 & $1.73(1.25)$ & 17 & $2.24(1.25)$ & 0.14 & 0.41 \\
\hline \multicolumn{7}{|l|}{ Potential reasons for $R R M / R R B S O$} \\
\hline Diagnosed cancer & 67 & $3.16(0.90)$ & 21 & $3.43(0.81)$ & 0.23 & 0.31 \\
\hline Cancer incidence in the family & 68 & $2.18(1.12)$ & 20 & $2.70(1.17)$ & 0.07 & 0.46 \\
\hline Fear of getting cancer & 66 & $2.00(1.36)$ & 18 & $2.72(1.18)$ & $0.04^{*}$ & 0.54 \\
\hline Assumed stronger benefits compared to intensified screening & 70 & $2.42(0.96)$ & 20 & $2.23(0.82)$ & 0.40 & -0.20 \\
\hline \multicolumn{7}{|l|}{ Potential reasons against $R R M / R R B S O$} \\
\hline Importance of physical attractiveness for self-esteem & 67 & $2.83(0.84)$ & 19 & $3.13(0.94)$ & 0.37 & 0.35 \\
\hline Fear of never feeling healthy again & 67 & $2.25(1.18)$ & 16 & $2.18(1.13)$ & 0.82 & -0.06 \\
\hline Fear of weight gain and menopausal symptoms & 66 & $2.35(1.07)$ & 18 & $2.00(1.46)$ & 0.28 & -0.30 \\
\hline Fear of loss of attractiveness & 66 & $2.52(1.11)$ & 19 & $2.78(1.00)$ & 0.37 & 0.24 \\
\hline Fear of rejection by the partner & 67 & $1.88(1.02)$ & 19 & $2.05(0.98)$ & 0.52 & 0.17 \\
\hline Fear of disordered female identity & 67 & $2.14(0.94)$ & 19 & $2.08(1.00)$ & 0.80 & -0.06 \\
\hline Fear of surgical measures & 67 & $2.02(1.15)$ & 19 & $2.08(1.23)$ & 0.85 & 0.05 \\
\hline Fear of interferences with sex life & 67 & $2.05(1.04)$ & 19 & $2.16(1.12)$ & 0.70 & 0.12 \\
\hline
\end{tabular}

ES, effect size; $d$, Cohen's $d$; RRM, risk-reducing mastectomies; RRBSO, risk-reducing bilateral salpingo-oophorectomy. ${ }^{*} p<0.05$.

Table 3. Hierarchical logistic regression of objective and psychological factors predicting RRM or RRBSO

\begin{tabular}{|c|c|c|c|c|}
\hline Variables & $B$ & SE B & $e^{\mathrm{B}}$ & $p$ \\
\hline Parity (at least one child) & 2.06 & 0.91 & 7.83 & $0.03 *$ \\
\hline$B R C A 1$ versus not & 1.97 & 0.80 & 7.15 & $0.01^{*}$ \\
\hline$B R C A 2$ versus not & 2.18 & 0.96 & 8.88 & $0.02^{*}$ \\
\hline Perceived effect of RRBSO & 0.41 & 0.41 & 1.51 & 0.31 \\
\hline Reason for screening: need for safety in health issues & 0.97 & 0.49 & 2.63 & $0.047^{*}$ \\
\hline Reason for screening: fear of far-reaching therapeutic measures & 0.06 & 1.09 & 1.06 & 0.96 \\
\hline Reasons for RRM/RRBSO: fear of getting cancer & 0.26 & 0.26 & 1.29 & 0.33 \\
\hline
\end{tabular}

RRM, risk-reducing mastectomies; RRBSO, risk-reducing bilateral salpingo-oophorectomy. Nagelkerke $R^{2}=0.40 ;{ }^{*} p<0.05$.

After consultation, only 21 out of our 95 patients had undergone prophylactic surgeries. This is a smaller percentage than that reported in previous studies $[13,20]$. Especially RRM were low. Older age of the participants of our study and a short follow-up period could explain these differences.

We detected that decision-making for prophylactic surgeries is influenced by objective factors such as detect- 
ed $B R C A 1 / B R C A 2$ mutation. These findings support previous studies that described that $B R C A 1 / B R C A 2$ mutation carriers more often opted for prophylactic surgeries than women with an increased lifetime risk [1]. Thus, the objective risk information by genetic counselling seems to be of importance for decision-making $[21,22]$. We hypothesized that apart from personal history, family history could also have an impact on decision-making towards prophylactic surgeries.

In a previous study, the desire to live longer for the family was also found to be a predictive factor for prophylactic surgeries [23]. In accordance to this observation, we found that parity was a significant predictive factor for the uptake of prophylactic surgeries.

As mentioned above, emotional factors have been shown to affect women's decisions for RRM/RRBSO [2325].

Knowing about the increased risk of developing cancer induces multiple worries: the one that matters most is the fact to develop cancer. Consistent with other studies, we found that the fear of getting cancer and of the burden associated with the treatment after cancer diagnosis are important predictive factors for choosing prophylactic surgeries $[16,20,25,26]$. Especially, anxiety for BC seems to matter for the uptake of RRM $[21,22,27]$. Those women who chose RRBSO also had the perception of the preventive effect of this procedure. However, if all these factors are included simultaneously within a logistic regression analysis, the need for safety in health issues (as a reason for participating in the screening) remains the only psychological predictor of the decision for prophylactic surgery.

Despite the already high cancer risk in these persons, there is still substantial variability with regard to the health safety need, and predominantly those with a high safety need choose the rational decision of prophylactic surgery. This result shows that there is still a great need for counselling, so that all persons with an increased cancer risk see this as a real danger.

Previous studies reported that women worry that RRM/RRBSO can be followed by negative change in the body image and changes in sexual attractiveness, especially for women who have operative complications [28]. However, loosing attractiveness, rejection of the partner, or interferences with sexual life did not affect decisionmaking in our study. Additionally, worries about menopausal complaints or about the surgeries themselves did not affect decision-making in our study. These differences could be due to the older age of the investigated group herein.

\section{Strengths and Limitations}

The strength of our study is that we had a relatively homogenous collective concerning demographic charac- teristics (age, BMI, etc.) that is representative for the German Consortium for Hereditary Breast and Ovarian Cancer. However, the study has some limitations. The sample size is relatively small, and few women of younger age were included, which explains some differences to other studies. Previous studies demonstrated that the uptake of prophylactic surgeries is dependent on time [1]. Thus, RRBSO was likely to occur 2 years after genetic testing in women between 35 and 45 years [1]. Due to the design of our study, we were not able to demonstrate the dependence of decision-making on time of all our patients as the time of their genetic counselling varied.

Additionally, the short follow-up could be one reason for the low rate of prophylactic surgeries. Even though cultural or religious background was not specially assessed, we did not find significant differences in healthrelated issues in the group opting for/against prophylactic surgeries.

The risk of developing BC or OC is also modified by lifestyle factors such as smoking [29, 30], obesity [31, 32] or physical activity [33]. It is known that penetrance of $B R C A 1 / B R C A 2$ is also dependent on these risk factors $[30,34,35]$. Thus, smoking was associated with increased $\mathrm{BC}$ risk in BRCA2 mutation carriers [30]. However, patients included in our study - who already had a counseling about risk factors and modifiers - had a high probability of following a healthy lifestyle. Indeed, we showed that $81 \%$ were physically active, and $80 \%$ denied smoking, which shows that most of the patients were aware of the effects. This may have led to a reduction of lifestyle effects on decision-taking for or against surgery.

\section{Conclusion}

Predictive factors to opt for prophylactic surgeries among women with BRCA1/BRCA2 mutation/high family risk of $\mathrm{BC} O C$ are verified mutation status, parity, a higher need for safety in health issues, and fear of getting cancer/therapeutic measures after cancer diagnosis. As prophylactic surgeries have been shown to reduce cancer incidence and - at least for RRBSO even mortality - in contrast to periodic screening, providing more information about the benefits and reducing fear is necessary. During counselling, psychological aspects that could affect women after prophylactic surgeries should also be addressed.

\section{Acknowledgement}

The subjects of our study have given their written informed consent. The study protocol has also been approved by the research institute's committee on human research. 


\section{Statement of Ethics}

Ninety-five study participants were recruited between January and August 2012 from the outpatient department of the University of Würzburg participating in the German Consortium for Hereditary Breast and Ovarian Cancer. The study was approved by the institutional review board of the hospital.

\section{Disclosure Statement}

The authors have no conflicts of interest to declare.

\section{Author Contributions}

R.S. provided the study design, did the data analysis, and interpreted the results. C.P. collected the data and also participated in the data analysis. S.H. participated in the data collection. U.K. and A.W. checked the design of the study and revised the study for intellectual content. S.S. drafted the manuscript, analyzed, and interpreted the results. All authors have read and have approved the final manuscript.

\section{References}

1 Lalloo F, Evans DG. Familial breast cancer. Clin Genet. 2012 Aug;82(2):105-14.

2 Meindl A, Ditsch N, Kast K, Rhiem K, Schmutzler RK. Hereditary breast and ovarian cancer: new genes, new treatments, new concepts. Dtsch Arztebl Int. 2011 May; 108(19):323-30.

3 Kauff ND, Domchek SM, Friebel TM, Robson ME, Lee J, Garber JE, et al. Risk-reducing salpingo-oophorectomy for the prevention of BRCA1- and BRCA2-associated breast and gynecologic cancer: a multicenter, prospective study. J Clin Oncol. 2008 Mar;26(8): 1331-7.

4 Rebbeck TR, Kauff ND, Domchek SM. Metaanalysis of risk reduction estimates associated with risk-reducing salpingo-oophorectomy in BRCA1 or BRCA2 mutation carriers. J Natl Cancer Inst. 2009 Jan;101(2):80-7.

5 Kuchenbaecker KB, Hopper JL, Barnes DR, Phillips KA, Mooij TM, Roos-Blom MJ, et al.; BRCA1 and BRCA2 Cohort Consortium. Risks of Breast, Ovarian, and Contralateral Breast Cancer for BRCA1 and BRCA2 Mutation Carriers. JAMA. 2017 Jun;317(23):240216

6 Li X, You R, Wang X, Liu C, Xu Z, Zhou J, et al. Effectiveness of Prophylactic Surgeries in BRCA1 or BRCA2 Mutation Carriers: A Meta-analysis and Systematic Review. Clin Cancer Res. 2016 Aug;22(15):3971-81.

7 Domchek SM, Friebel TM, Neuhausen SL, Wagner T, Evans G, Isaacs C, et al. Mortality after bilateral salpingo-oophorectomy in BRCA 1 and BRCA 2 mutation carriers: a prospective cohort study. Lancet Oncol. 2006 Mar;7(3):223-9.

8 Domchek SM, Friebel TM, Singer CF, Evans DG, Lynch HT, Isaacs C, et al. Association of risk-reducing surgery in BRCA1 or BRCA2 mutation carriers with cancer risk and mortality. JAMA. 2010 Sep;304(9):967-75.

9 Eleje GU, Eke AC, Ezebialu IU, Ikechebelu JI, Ugwu EO, Okonkwo OO. Risk-reducing bilateral salpingo-oophorectomy in women with BRCA1 or BRCA2 mutations (Review). Cochrane Database Syst Rev. 2018 Aug 8:CD012464.
10 Singh K, Lester J, Karlan B, Bresee C, Geva T, Gordon O. Impact of family history on choosing risk-reducing surgery among BRCA mutation carriers. Am J Obstet Gynecol. 2013 Apr;208(4):329.e1-6.

11 Saadatmand S, Obdeijn IM, Rutgers EJ, Oosterwijk JC, Tollenaar RA, Woldringh GH, et al. Survival benefit in women with BRCA1 mutation or familial risk in the MRI screening study (MRISC). Int J Cancer. 2015 Oct; 137(7):1729-38.

12 Metcalfe KA, Birenbaum-Carmeli D, Lubinski J, Gronwald J, Lynch H, Moller P, et al.; Hereditary Breast Cancer Clinical Study Group. International variation in rates of uptake of preventive options in BRCA1 and BRCA2 mutation carriers. Int J Cancer. 2008 May;122(9):2017-22.

13 Schott S, Vetter L, Keller M, Bruckner T, Golatta M, Eismann S, et al. Women at familial risk of breast cancer electing for prophylactic mastectomy: frequencies, procedures, and decision-making characteristics. Arch Gynecol Obstet. 2017 Jun;295(6):1451-8.

14 Gavaruzzi T, Tasso A, Franiuk M, Varesco L, Lotto L. A Psychological Perspective on Factors Predicting Prophylactic Salpingo-Oophorectomy in a Sample of Italian Women from the General Population. Results from a Hypothetical Study in the Context of BRCA Mutations. J Genet Couns. 2017 Oct;26(5): 1144-52.

15 Frost MH, Slezak JM, Tran NV, Williams CI, Johnson JL, Woods JE, et al. Satisfaction after contralateral prophylactic mastectomy: the significance of mastectomy type, reconstructive complications, and body appearance. J Clin Oncol. 2005 Nov;23(31):7849-56.

16 Glassey R, O’Connor M, Ives A, Saunders C, Hardcastle SJ; kConFab Investigators. Influences on decision-making for young women undergoing bilateral prophylactic mastectomy. Patient Educ Couns. 2018 Feb;101(2): 318-23.

17 Stuckey AR, Onstad MA. Hereditary breast cancer: an update on risk assessment and genetic testing in 2015. Am J Obstet Gynecol. 2015 Aug;213(2):161-5.

18 Goel NS. Angelina's choice. South Asian J Cancer. 2013 Oct;2(4):285-7.
19 Borzekowski DL, Guan Y, Smith KC, Erby LH, Roter DL. The Angelina effect: immediate reach, grasp, and impact of going public. Genet Med. 2014 Jul;16(7):516-21.

20 Madalinska JB, van Beurden M, Bleiker EM, Valdimarsdottir HB, Lubsen-Brandsma L, Massuger LF, et al. Predictors of prophylactic bilateral salpingo-oophorectomy compared with gynecologic screening use in BRCA1/2 mutation carriers. J Clin Oncol. 2007 Jan; 25(3):301-7.

21 Meiser B, Butow P, Barratt A, Friedlander M, Gattas M, Kirk J, et al. Attitudes toward prophylactic oophorectomy and screening utilization in women at increased risk of developing hereditary breast/ovarian cancer. Gynecol Oncol. 1999 Oct;75(1):122-9.

22 van Dijk S, Otten W, Zoeteweij MW, Timmermans DR, van Asperen CJ, Breuning $\mathrm{MH}$, et al. Genetic counselling and the intention to undergo prophylactic mastectomy: effects of a breast cancer risk assessment. Br J Cancer. 2003 Jun;88(11):1675-81.

23 Lloyd SM, Watson M, Oaker G, Sacks N, Querci della Rovere U, Gui G. Understanding the experience of prophylactic bilateral mastectomy: a qualitative study of ten women. Psychooncology. 2000 Nov-Dec;9(6):473-85.

24 van Driel CM, Oosterwijk JC, Meijers-Heijboer EJ, van Asperen CJ, Zeijlmans van Emmichoven IA, de Vries J, et al. Psychological factors associated with the intention to choose for risk-reducing mastectomy in family cancer clinic attendees. Breast. 2016 Dec;30:6672

25 Fang CY, Miller SM, Malick J, Babb J, Hurley $\mathrm{KE}$, Engstrom PF, et al. Psychosocial correlates of intention to undergo prophylactic oophorectomy among women with a family history of ovarian cancer. Prev Med. 2003 Nov; 37(5):424-31.

26 Lodder LN, Frets PG, Trijsburg RW, MeijersHeijboer EJ, Klijn JG, Seynaeve C, et al. One year follow-up of women opting for presymptomatic testing for BRCA1 and BRCA2: emotional impact of the test outcome and decisions on risk management (surveillance or prophylactic surgery). Breast Cancer Res Treat. 2002 May;73(2):97-112. 
27 Hatcher MB, Fallowfield L, A'Hern R. The psychosocial impact of bilateral prophylactic mastectomy: prospective study using questionnaires and semistructured interviews. BMJ. 2001 Jan;322(7278):76.

28 Hopwood P, Lee A, Shenton A, Baildam A, Brain A, Lalloo F, et al. Clinical follow-up after bilateral risk reducing ('prophylactic') mastectomy: mental health and body image outcomes. Psychooncology. 2000 Nov-Dec; 9(6):462-72.

29 Croghan IT, Pruthi S, Hays JT, Cha S, Johnson RE, Kosel M, et al. The role of smoking in breast cancer development: an analysis of a Mayo Clinic cohort. Breast J. 2009 Sep-Oct 15(5):489-95.
30 Friebel TM, Domchek SM, Rebbeck TR. Modifiers of cancer risk in BRCA1 and BRCA2 mutation carriers: systematic review and meta-analysis. J Natl Cancer Inst. 2014 Jun;106(6):dju091.

31 Park J, Morley TS, Kim M, Clegg DJ, Scherer PE. Obesity and cancer-mechanisms underlying tumour progression and recurrence. Nat Rev Endocrinol. 2014 Aug;10(8):455-65.

32 Rose DP, Gracheck PJ, Vona-Davis L. The Interactions of Obesity, Inflammation and Insulin Resistance in Breast Cancer. Cancers (Basel). 2015 Oct;7(4):2147-68.

33 Lahart IM, Metsios GS, Nevill AM, Carmichael AR. Physical activity, risk of death and recurrence in breast cancer survivors: A sys- tematic review and meta-analysis of epidemiological studies. Acta Oncol. 2015 May;54(5): 635-54.

34 Bissonauth V, Shatenstein B, Fafard E, Maugard C, Robidoux A, Narod S, et al. Weight History, Smoking, Physical Activity and Breast Cancer Risk among French-Canadian Women Non-Carriers of More Frequent BRCA1/2 Mutations. J Cancer Epidemiol. 2009;2009:748367.

35 Guinan EM, Hussey J, McGarrigle SA, Healy LA, O’Sullivan JN, Bennett K, et al. A prospective investigation of predictive and modifiable risk factors for breast cancer in unaffected BRCA1 and BRCA2 gene carriers. BMC Cancer. 2013 Mar;13(1):138. 